\title{
INOVAÇÃO E REPRESENTAÇÕES SOCIAIS DE DIRIGENTESDAS EMPRESAS DE um Polo TeCNOLÓgico
}

Jackeline Amantino de Andrade

Dautara emAdministracão pda Univesidade

Feelaral doRioGrandedoSul eProfessara do

DepartamentodeCiênias Administrativasedb Propad- Universidade Federal dePernanburo

Isabely Sales de Almeida Muniz Graduanda emAdministraçãopda UniversidadeFeeleral dePernambuco

Cecília Ângelo da Silva Graduanda emAdministracãopda Universidade Feedal dePernamburo

O que tem caracterizado o mundo contemporâneo é a atração pela novidade e o entendimento de que há uma mudança sem precedentes, principalmente quando considerados os avanços tecnológicos, propiciados pelas tecnologias de informação e comunicação (TICS). Nesse sentido, G rey (2004) afirma que a mudança tornou-se quase um fetiche, devendo ser analisada em relação às práticas e às representações sociais. Partindo desses pressupostos, este artigo apresenta os resultados de pesquisa realizada junto a dirigentes de empresas instaladas num polo tecnológico no nordeste brasileiro, de modo a analisar quais são as suas representações sociais relativas à inovação, comparando-as com as classificações e tipologias definidas na literatura.

Palavras-chave: Inovação Tecnológica. Inovação Organizacional. Representação Social. Tecnologia de Informação e Comunicação. Polo Tecnológico.
Thecontemporary world has been dharacteized by theattraction of novdty and theundestanding that thereis an unpreeelenteel dhange, espeeially when consideing thetechnological advances enabled by in formation and commmication techndoyy (ICT). In thissense, Grey (2004) daims that dhangehas beecmealmost a feish and should be consideredin reation to thepradicesand scial representations Taking theseassumptions into account, this paper presents theresits of a survey responded by business leades in a technoloyy park located in northeastem Brazil in order toanalyzewhat aretheir soial representations in reation to inmovation bycomparing them to the dassifications and types definedin theery.

Keywords: Techndogical Innoation Organizational Innowation Social Representation Information and Commmication Teehndogy. Techndogy Park. 


\section{INTRODUÇÃO}

Uma das grandes características do mundo contemporâneo é a atração pela novidade, que faz com que a noção de mudança surja de forma muito mais intensa. A ideia de inovação parece cada vez mais próxima e domina a sociedade atual. Segundo Grey (2004), a mudança tomou uma centralidade nos argumentos que envolvem a sociedade, e principalmente as organizações, que necessidade ser compreendido "não independentemente das nossas práticas e representações coletivas.

Assim, o tema inovação em seus mais diversos aspectos tornou-se uma importante área de pesquisa ao longo das últimas décadas. Por ter um caráter multidisciplinar, o tópico tem sido tratado de forma ampla e diversa que, por consequência, traz consigo uma série de variações quanto ao seu conceito e à sua classificação.

Considerando a sua importância para o mundo contemporâneo e, principalmente, para a realidade das organizações, a inovação também tem forte presença e relevância na área de Administração. Essa disciplina tem direcionado em especial sua atenção à inovação tecnológica em produtos e processos, sobretudo para as empresas, mas também a contextos mais amplos da análise organizacional. A inovação tecnológica traz uma série de vantagens, mensuradas não apenas em curto prazo, como a rentabilidade, mas também em longo prazo, como o crescimento das empresas. Assim, outros fatores devem ser considerados, pois a inovação não é algo somente voltado para a mudança tecnológica, envolvendo alterações no conjunto amplo que constituiu a organização e na operação de suas atividades.

Além disso, cada vez mais têm sido salientados elementos sociais inerentes à inovação, levando à compreensão de que, neste século, ela adquire contornos de um fenômeno cultural. Portanto, se a inovação é "conhecimento economicamente útil" (Bruland \& Mowery, 2005, p. 359), também aporta em si as promessas de um progresso tecnológico que pode se reverter na melhoria da qualidade de vida das sociedades. D essa forma, a inovação tem sido compreendida como fator de geração de novas soluções para problemas, satisfazendo as necessidades dos indivíduos e das sociedades, conforme propõe o Green Paper on Innovation, da Comunidade Europeia.

No Brasil, tampouco é diferente. 0 Livro Branco, que trata das estratégias da política nacional de ciência, tecnologia e inovação neste milênio, firma que o cenário da economia mundial demanda "pela conquista de competitividade entre as economias nacionais", vinculando-a à "capacitação tecnológica de geração e incorporação de inovações tecnológicas aos produtos e aos processos", que, por outro lado, servem para alcançar "o próprio bem-estar das populações" na produção de bens e serviços em menor custo "que melhorem a sua qualidade de vida" (Brasil, 2002).

A partir do entendimento da inovação como um fenômeno cultural e organizacional que, como destaca Grey (2004), não é independente das práticas e das representações coletivas, este artigo tem como objetivo discutir a incorporação da inovação nos conceitos e nas práticas dos gestores de empre- sas brasileiras. Para tanto, foi realizada uma pesquisa junto a dirigentes de quatro empresas pertencentes ao Porto Digital, um polo tecnológico instalado na cidade do Recife, Pernambuco, que desde 0 ano de 2000 desenvolve atividades relacionadas às novas tecnologias da informação e comunicação (TICs). 0 artigo organiza-se a partir desta introdução, seguida de referencial que trata da conceituação e tipologia de classificação da inovação, como também da teoria das representações sociais, justificada em função dos procedimentos metodológicos adotados na pesquisa, explicitados no item que se segue, centrado em identificar as representações sociais desses dirigentes relativas à inovação. $\mathrm{D}$ ando seguimento ao trabalho são analisados os resultados, evidenciando as diferentes representações sociais dos dirigentes e levantando a adequação da tipologia classificatória adotada. Finalmente, são tecidas considerações finais sobre os achados da pesquisa, sendo indicados novos pontos a ser investigados por futuras pesquisas.

\section{CONCEITUANDO A INOVAÇÃO}

No que tange ao conceito de inovação, não existe uma definição adotada consensualmente pelos diversos estudiosos da área. Segundo Barbieri e Álvares (2004, apudAndreassi, 2007), o verbo inovar vem do latim inmoraree significa renovar ou introduzir novidades de qualquer espécie. Já inovação é um termo variante e quer dizer renovado ou tornado novo.

Além de denotar novidade e mudança, a inovação é abordada, segundo relatório apresentado pela Comunidade Europeia (GreenPaperonInnovation), como "um sinônimo para produção, assimilação e exploração com sucesso de novidades nas esferas econômicas e sociais. [Esta] oferece novas soluções para problemas e assim torna possível satisfazer as necessidades tanto do indivíduo como da sociedade" (European Comission, 1995, p. 2, apudMoreira \& Q ueiroz, 2007).

Na visão de Zaltman, Duncan e Holbek (1973, apud Moreira \& Queiroz, 2007), a inovação é "qualquer ideia, prática ou artefato material percebido como novo pela unidade de adoção relevante, a qual pode ser uma pessoa, uma organização, um setor industrial, uma região, etc". Por sua vez, Motta (1997) salienta que inovar "é introduzir a novidade de tal forma a deixar explícita que alguma tecnologia, habilidade ou prática organizacional se tornou obsoleta", estando implicada numa "visão de progresso, que carrega a conotação da virtude e do mais bem realizado."

Como pode ser observado a partir dessas conceituações, há uma conformidade em dizer que inovação é tudo o que é novo, como também é a introdução de novidade de qualquer espécie em determinado contexto. No entanto, não há de fato uma clareza quanto ao que pode ser considerado como tal.

A inovação é algo percebido de forma indireta, o "novo" tem diversas formas de ser entendido, podendo denotar sucesso na solução de um antigo problema, constituir-se numa nova percepção em relação ao contexto ou um progresso, ou numa superação daquilo que se tornou ultrapassado. Considerando essas diferentes maneiras de se perceber o que é novo - renovação ou progresso - , surge o questionamento sobre quão "novo" algo deve ser para ser considerado inovação. 
Nos últimos anos, o tema inovação, por sua diversidade de conceituações e tipologias, vem sendo tratado sob diferentes aspectos ao considerar parâmetros sociais, culturais, históricos, econômicos e, sobretudo, tecnológicos. É, no entanto, na dimensão tecnológica que a definição do termo é percebida de maneira mais concreta, já que a tecnologia é uma constante na história da humanidade e tem se difundido cada vez mais ao longo do tempo, estando presente em todos os campos da vida humana.

Com isso, a inovação tecnológica acabou se tornando quase um sinônimo de inovação como um todo. Quando se pensa sobre 0 assunto vem logo à cabeça aparelhos super modernos, novas tecnologias, entre outras coisas. Mas, na verdade, como explicitado acima, o conceito e a ideia de inovação vão muito além da tecnologia que, ao envolver uma série de áreas do conhecimento, deixa sua definição ainda cercada por uma série de interrogações à medida que se parte de diferentes pressupostos teóricos na explicação do fenômeno.

Não obstante, há também uma série de semelhanças nas pesquisas, em que todas as ideias convergem a um ponto central comum, a novidade, seja ela como superação do obsoleto, seja como o sucesso na solução de um problema; compreendida tanto pela ótica de quem a adota como pelo contexto no qual foi inserida. D estaca-se também a definição de Schumpeter de que a inovação é um novo bem, um novo método, um novo mercado, uma nova fonte de matéria-prima ou uma nova estrutura organizacional. (Andreassi, 2007, p. 15).

Cabe lembrar, no entanto, que as ideias de Schumpeter são fundamentalmente econômicas, ou seja, em conformidade com a ideia de Bruland \& Mowery (2005, p. 359) de que a inovação é o "conhecimento economicamente útil." Nesse sentido, destacam-se as empresas como aquelas capazes de gerar inovação e, consequentemente, riqueza para o progresso da sociedade dentro da tradição do pensamento econômico que remonta a Adam Smith.

Tem-se, portanto, a empresa como o mecanismo primordial para a criação e o aprimoramento da inovação, pelo desenvolvimento de novos produtos ou processo dentro dos preceitos do Manual de O slo (OECD, 1992). Tal desenvolvimento ocorre num contexto organizacional que "é extremamente amplo [abrangendo] todas as funções, da pesquisa aos serviços, incluindo tanto o markeingquanto a engenharia, tanto 0 design quanto a fabricação" (Leonard-Barton, 1998, p. 13). Ou seja, além de multidisciplinar, que "nenhuma só disciplina dá conta de todos os seus aspectos", esse fenômeno complexo que é a inovação (Fagerberg, 2005, p. 9) envolve também aspectos relativos à gestão organizacional (Motta, 1997).

\subsection{Classificando a inovação}

Foram definidas tipologias para a inovação, entre as várias possíveis. Como explicitado anteriormente, existem pontos em comum entre as todas as conceituações de inovação que devem ser melhor explorados a fim de explicar seus variados aspectos. Uma classificação bastante referenciada é a de Damanpour, que analisou a inovação com o intuito de identificar constructos que possibilitassem a sua compreensão mais aprofundada e, assim, permitissem conhecer as fontes de inovação nas organizações.

Para o autor (1991, apudMoreira \& Queiroz, 2007) existem categorias que se fundem, formando três classificações, sendo necessário entender os tipos e conceitos de inovação para se compreender a sua adoção e seus determinantes. Essa classificação se divide em: inovação administrativa e técnica ou tecnológica; inovação no produto e no processo, e inovação radical e incremental.

A inovação administrativa ou organizacional "está diretamente ligada à gerência da organização" (Moreira \& Queiroz, 2007, p. 10), e se refere a mudanças diretamente aplicadas aos processos administrativos, ou seja, é caracterizada pela implementação de novos sistemas que tragam conhecimentos e melhorias às práticas internas da organização. De forma sintética, esse tipo de inovação relaciona-se com a aplicação de novos métodos que tragam benefícios, possibilitando uma maior facilidade e conforto no alcance de metas, e resultando em uma melhor produtividade.

Já a inovação técnica ou tecnológica "diz respeito a produtos e tecnologias do processo produtivo, e está especialmente relacionada às atividades operacionais da produção" (apudMoreira \& Queiroz, 2007). Para ser considerada como tal, basta uma novidade estar ligada à implementação de um produto e/ ou processo novo (ou substancialmente aprimorado) internamente, não estando condicionado ao novo para o mercado ou para o setor econômico. Em síntese, a inovação tecnológica, nas palavras de Tornatzky e Fleischer (1990, apud Moreira \& Queiroz, 2007, p. 11), "é um evento nãousual, durante o qual a organização muda (pouco ou muito) o que faz e como faz.".

O utra divisão da classificação é entre inovação no produto e no processo. A primeira busca atender às necessidades do cliente, e a segunda refere-se aos novos elementos utilizados nas operações de produção e serviços. A inovação no produto relaciona-se ao desenvolvimento de ideias adquiridas por meio de fontes internas ou externas no desenvolvimento do conceito de um novo produto, que serão testadas e analisadas para sua posterior introdução no mercado, enquanto a inovação no processo refere-se ao novo, aplicado aos processos a fim de reduzir custos, aumentar a velocidade da produção, ou aprimorar a qualidade do produto para melhor satisfazer o público-alvo. Existem autores que colocam esse tipo de inovação como uma reengenharia de processos, que prevê uma modificação superficial da atividade de produção.

Essas duas classificações são bastante complementares de tal modo que é possível compreender quais inovações no produto ou no processo tenham como consequência inovações tecnológicas e vice-versa. Como mostram Moreira e Queiroz (2007, p. 11), "muitas das inovações no produto e no processo são também inovações tecnológicas." Porém, é preciso distinguir entre as inovações tecnológicas em produtos e aquelas relacionadas aos processos, relativas a propósitos ou usos nos quais tecnologias/ ferramentas são empregadas, como também nos critérios adotados para atestar sua eficácia. 
Ao mesmo tempo, um afastamento de práticas e de mecanismos habitualmente adotados na organização abre espaço para uma terceira classificação: inovação radical e inovação incremental. Alterações (técnicas, administrativas, de processo ou de produtos) que constituem "adaptações menores nas rotinas organizacionais existentes e que se ajustam a normas e valores dos membros da organização" são classificadas como inovação incremental (Moreira \& Q ueiroz, 2007, p. 12). É possível afirmar que a ocorrência desse tipo de inovação é bastante comum, como também que ela pode levar a algo maior e duradouro, à medida que incrementos no processo podem, por exemplo, resultar em um processo completamente novo. Por outro lado, mudanças não cotidianas, que modificam significativamente as rotinas, incluindo o rompimento com os antigos valores e práticas organizacionais, são classificadas como inovação radical.

\section{REPRE SE NTAÇÕE S SOCIAIS}

As representações sociais são o saber gerado a partir do senso comum. Tal conceito advém da psicologia social, mais especificamente da teoria das representações sociais desenvolvida por Serge Moscovici, na França, no final dos anos cinquenta do século passado (Vergara \& Ferreira, 2005). Para Moscovici, é necessário considerar o sujeito como parte de um conjunto indissociável com o objeto e a sociedade, no entendimento do conhecimento de senso comum, sendo as representações sociais conceitos e explicações originados do cotidiano e das inter-relações sociais, que podem ser comparadas aos mitos e às crenças das sociedades tradicionais estudadas pela antropologia (Moscovici, 1978).

Nesse sentido, as representações sociais poderiam ser compreendidas como um elemento cultural compartilhado por determinada comunidade, isto é, uma percepção comum relativa a determinado fenômeno, simbologias partilhadas. Entretanto, deve-se ressaltar que aquilo que fundamenta a representação social é fundamentalmente a forma de atribuição de significado do indivíduo em relação aos objetos constituintes do seu cotidiano, que, certamente, é marcado por interações sociais. Assim, é preciso considerar as constituições simbólicas feitas pelos indivíduos no mundo que lhes é próximo e no qual eles estão engajados cotidianamente, compreendendo que as representações sociais são aquelas que orientam 0 universo de entendimento e de possibilidades à disposição dos indivíduos (Cramer, Mozar \& Cappelle, 2001).

Como destacam Vergara e Ferreira (2005, p. 1141), "as representações sociais não são reflexo da realidade e sim construções mentais dos objetos, inseparáveis das atividades simbólicas dos sujeitos e de sua inserção na totalidade social" que, conforme Cavedon e Ferraz (2005), constituem-se em teorias de senso comum que ao ser interiorizadas permitem a organização da realidade, à medida que torna aquilo que é estranho em familiar, transformando uma abstração em algo concreto para o indivíduo. As representações sociais são, assim, "modalidades de conhecimento prático orientadas para a comunicação e para a compreensão do contexto social, material e ideativo em que vivemos" (Spink, 1993, p. 300).
Nóbrega (1990) propõe à compreensão dessa modalidade 0 conhecimento que influencia aspectos ideacionais e as práticas dos indivíduos em relação a um objeto social, em particular a partir da objetivação e da ancoragem. A objetivação possibilita corporificar 0 abstrato por meio de uma construcãa sdetiva em que é apropriado certo conteúdo teórico-científico transformado em senso comum, baseado na esquematização estruturante, que organiza a natureza do fenômeno (objeto) e sua relação com o indivíduo, e na maturalização em que 0 abstrato se reflete no real, ou seja, o indivíduo dá uma concretude ao fenômeno (objeto). A ancoragem ocorre por meio da atribuiçãodosentida em que se busca a adequação de novos conhecimentos àqueles já existentes; da instrumentalização do saber, que transforma esse novo conhecimento em saber utilizável, e do enraizamentodopensamertopor meio do qual essa novidade é incorporada.

Assim, tendo essa compreensão das representações sociais como formas práticas de conhecimento, isto é, de como 0 abstrato é apropriado pelo senso comum, é possível investigar como a inovação constitui-se numa construção mental e torna-se familiar para aqueles que cotidianamente com ela trabalham. É particularmente interessante fazer essa indagação quando considerada a abertura conceitual existente na literatura.

\section{PROCEDIMENTOS METODOLÓGICOS}

Esta pesquisa teve um caráter exploratório-descritivo que, conforme Gil (2008), visa basicamente esclarecer conceitos e ideias com o objetivo de descrever as características de determinado fenômeno. Algo bastante pertinente à inovação que ainda demanda por um consenso em relação à sua conceituação.

Foi definido como universo da pesquisa o Porto Digital, que se constitui num polo tecnológico implantado na região nordeste brasileira, mais especificamente em Recife, estado de Pernambuco, caracterizado, em seu portal, como um "ambiente de inovação" que envolve "instituições, empresas, universidade e governos", para "fomentar mudanças econômicas e sociais" e gerar "riqueza, emprego e renda", desenvolvendo suas atividades ligadas às Tecnologias de Informação e Comunicação (TIC) desde 0 ano de 2000 (Porto Digital, 2008). Tal escolha se justifica, pois a ideia de inovação em uma relação simbiótica com o mundo dos negócios (O liveira e Sorgi, 2008) tem sido particularmente vinculada às novas tecnologias, como as TICs, sendo o Porto Digital um ambiente que embarca empresas totalmente direcionadas à inovação tecnológica, por meio do desenvolvimento, entre outros, de portais corporativos, intranets, extranets, games, websites, atendendo tanto setores econômicos como financeiros, o setor de tráfego aéreo, da saúde, de segurança, de transporte e de produção de softwares.

Assim, foi realizado um levantamento preliminar das organizações que constituem esse polo tecnológico, sendo identificado o conjunto de empresas embarcadas e sua principal atividade. Foi, então, definida uma amostra intencional de quatro empresas, tendo como critério um contínuo da- 
quelas que exerciam atividades mais tradicionais na área, como o desenvolvimento de sistemas de informação, e aquelas que trabalhavam com elementos mais inovadores - como jogos e inteligência artificial.

Dado o objetivo da pesquisa, que era identificar as representações sociais atribuídas pelos dirigentes das empresas do Porto Digital relativas à inovação, a coleta de dados foi realizada por meio de entrevistas com base na técnica da entrevista narrativa, que facilita "uma situação que encoraje e estimule 0 entrevistado a contar uma história sobre algum acontecimento importante de sua vida e do contexto social" (Bauer e Gaskel, 2003, p. 93). Tal escolha se justifica quando se considera que "toda representação é sempre uma representação de alguma coisa ou de alguém" (Nóbrega, 1990), e é uma interpretação da realidade que revela como o indivíduo constrói um conjunto lógico de pensamento e significação, constituindo sua visão de mundo e da coletividade da qual faz parte (Jovechlovitch, 2000). Ao todo foram realizadas quatro entrevistas com os dirigentes de cada uma das empresas selecionadas pela amostra, com o objetivo de investigar como "o saber constituído pelas representações ajuda a compreender, reconstituir, interpretar os objetos cotidianos" (Rangel, 2004, p. 14).

A análise de dados foi realizada por meio de análises de conteúdo caracterizadas como "técnicas de análise de comunicações", que adotam "procedimentos sistemáticos" na "descrição de conteúdos" (Bardin, 1977). Por essa análise, buscou-se identificar conteúdos e categorizá-los a partir das classificações estabelecidas na literatura, sendo dispensada uma etapa intermediária relativa à codificação, pois, segundo D ellagnelo e Silva (2005), tal etapa não se constitui numa obrigatoriedade para a análise.

\section{ANÁLISE E DISCUSSÃO DOS RESULTADOS}

Aqui são apresentados, analisados e discutidos os resultados da pesquisa. Antes, porém, no item 5.1 é apresentada uma pequena descrição de cada uma das empresas, com 0 objetivo de caracterizar suas atividades e a sua dinâmica organizacional.

\subsection{Descrição das empresas}

A $\mathbf{N}$ é uma empresa de pequeno porte de prestação de serviços de consultoria na área de tecnologia da informação há mais de dez anos, estando há três vinculada ao Porto Digital. A organização iniciou suas atividades na área de infraestrutura de redes, e atualmente trabalha com o CRM (Customer Rdationship Management). Esse sistema auxilia 0 armazenamento de informações e 0 atendimento customizado num portfólio de clientes de pequenas e médias empresas.

Recentemente, essa empresa fez uma mudança nos processos de comunicação interna, adotando uma intranet. 0 controle administrativo foi incrementado com a implantação de ferramenta de medição de retorno das atividades junto aos clientes. Isso reflete a preocupação dessa empresa com 0 desempenho que busca incorporar a participação dos funci- onários na melhoria de processos, de modo a criar uma cultura corporativa direcionada à inovação.

A origem da empresa I data de 1996, na dedicação da atividade de provedor de acesso à internet. Em 1999, houve uma fusão com mais outras duas empresas, sendo criada a I, que trabalha com o desenvolvimento de web sites e projetos de sistemas que vão desde o planejamento de portais corporativos até hasitespromocionais e de otimização de busca (SEO- SearchEngineOptimization). Essa empresa trabalha com clientes de grande porte, inclusive conta com uma unidade de negócios e atendimento em São Paulo, por meio de parceria, sendo os seus serviços executados em Recife, Pernambuco. Ao mesmo tempo, a empresa tem investido na ampliação de sua carteira de clientes locais.

Há na empresa uma particularidade relativa aos seus recursos humanos, na sua maioria constituída de universitários incentivados ao constante aprendizado e aperfeiçoamento de habilidades, à troca de experiências externas, dinamizando a geração de conhecimento na organização com um foco no leaminglby-daingpara a execução de projetos, inclusos as fases de brieinge arquitetura da informação, de websitese portais corporativos. Também, o espaço físico é diferenciado com 0 intuito de facilitar a cooperação entre os funcionários e na geração de novas ideias, sendo utilizada uma intranet para administrar os projetos, como também facilitar a troca de mensagens.

A empresa $\mathbf{F}$ iniciou suas atividades como fabricante de software há cerca de 15 anos, entretanto com insucesso. Há cinco anos, ingressando no Porto Digital, foi redefinido o seu foco de negócio a partir de neworkingcom seus clientes. Passando a atuar no desenvolvimento de portais corporativos, especialmente intranets, essa empresa tem como objetivo fornecer soluções de identificação, armazenagem e organização, e distribuição de informação aos seus clientes tanto interna como externamente. Além disso, atua na área de apoio à decisão, utilizando recursos de multicritério, salas de situações, painéis de controle, centros de monitoramento, tendo a empresa optado por trabalhar também com soluções ligadas à Inteligência Artificial, que é uma área específica direcionada à elaboração de mecanismos computacionais, simulando a capacidade humana na solução de problemas.

Já a M é uma empresa que há seis anos trabalha com 0 desenvolvimento de conteúdo para celulares, principalmente jogos, sendo associada ao C.E.S.A.R. e à FIR Capital, distribuindo seus produtos junto às operadoras de telefonia móvel. A empresa opera por meio da gestão de projetos, sendo muitos dos seus profissionais certificados pelo PMI (Project Management Institute), e 0 acompanhamento dos projetos de cada equipe ocorre por reuniões semanais como também por recursos cotidianos de comunicação interna, como e-mails. Atualmente, a empresa tem buscado definir como seu core businessa comercialização de jogos para celulares, investindo na criação de uma fábrica de jogos, organizando sob bases de leamproduction, que permite o desenvolvimento de conteúdos em três semanas. Também busca uma ampliação de seus ne- 
gócios em novos mercados dos grandes centros brasileiros, como São Paulo, Rio de Janeiro e Belo Horizonte.

\subsection{As representações sociais da inovação de dirigentes de empresas do Porto Digital}

O Q uadro 1 a seguir apresenta uma síntese dos conteúdos identificados nas entrevistas com os dirigentes das empresas embarcadas no Porto Digital, em relação a sua compreensão sobre a inovação. A análise buscou estabelecer como esses dirigentes faziam suas construções seletivas a partir de esquematizações estruturantes para a naturalização do termo inovação, definindo uma atribuição de sentido que, como pode ser observado, revela-se pela adoção de algo novo no contexto da organização. ganizações, traduzido em técnicas, tecnologias, competências, objetivos, processos e produtos, de modo que esse saber relativo à inovação relaciona-se às práticas organizacionais.

Verificando-se a necessidade de se compreender melhor tais contextos organizacionais de inovação, segue uma pequena síntese desses contextos a partir daquilo que foi descrito pelos entrevistados.

No caso do dirigente da $\mathbf{N}$, o que se destaca é uma percepção da inovação vinculada às novas tecnologias adotadas, pois a empresa iniciou suas atividades direcionadas à infraestrutura de rede e hoje trabalha com o CRM. Também, há uma preocupação de inovar na gestão e no desenvolvimento da criatividade interna da empresa, destacandose a necessidade de aperfeiçoamento das competências dos

\begin{tabular}{|c|c|}
\hline Dirigente/ Empresa & Atribuição de sentido \\
\hline $\mathrm{N}$ & $\begin{array}{l}\text { - Alteração de serviços de consultoria na área de infraestrutura para tecnologia da informação; } \\
\text { - Adoção de nova atividade; } \\
\text { - Adoção de novos processos; } \\
\text { - Adoção de novas estratégias de consultoria; } \\
\text { - Adoção de novos sistemas de comunicação com o cliente; } \\
\text { - Adoção de novos sistemas de comunicação interna; } \\
\text { - Necessidade de novas competências dos funcionários; } \\
\text { - Mudança de cultura. }\end{array}$ \\
\hline I & $\begin{array}{l}\text { - Alteração de serviço, mudando de provedores de acesso para a construção de web sites; } \\
\text { - Adoção de nova atividade; } \\
\text { - Adoção de nova organização a fim de obter excelência; } \\
\text { - Adaptação dos projetos às demandas dos clientes; } \\
\text { - Adaptações técnicas e de processos de acordo com o cliente } \\
\text { - Adoção de meios novos internos na comunicação e de divulgação dos serviços; } \\
\text { - Necessidade de novas competências dos funcionários. }\end{array}$ \\
\hline $\mathrm{F}$ & $\begin{array}{l}\text { - Alteração do serviço de fabricação de softwares para consultoria em tecnologia; } \\
\text { - Adoção de nova atividade; } \\
\text { - Incorporação recente de novas áreas de atuação; } \\
\text { - Adoção de novos processos de atividade; } \\
\text { - Desenvolvimento de novos produtos } \\
\text { - Nova postura em relação aos funcionários (produtividade); } \\
\text { - Necessidade de novas competências dos funcionários; } \\
\text { - Mudança de objetivos. }\end{array}$ \\
\hline M & $\begin{array}{l}\text { - Adoção de novos processos de comercialização; } \\
\text { - Adoção de novas estratégias de divulgação; } \\
\text { - Mudança no tempo de desenvolvimento de jogos; } \\
\text { - Contínuo aprimoramento da criatividade dos funcionários; } \\
\text { - Valorização da aprendizagem. }\end{array}$ \\
\hline
\end{tabular}

Quadro 1: Atribuição dos sentidos da inovação pelos dirigentes

Fonte: Elaborado pelos autores, com base nos dados da pesquisa.

O bserva-se que três das quatro empresas alteraram a sua forma de operação ao longo do tempo, e somente a Meantime se constituiu dentro do novo paradigma tecnológico encetado por uma "revolução tecnológica" inerente às novas tecnologias da informação e comunicação (TICs). Pode-se, no entanto, verificar que em comum para esses dirigentes está a ideia de que a inovação tem somente concretude em relação as suas práticas organizacionais e de negócios cotidianos; a algo novo adotado no contexto de cada uma das or- funcionários e de melhora dos serviços de atendimento ao cliente tanto na forma como são elaborados quanto nos relacionamentos. Nesse sentido, há uma preocupação direcionada à melhoria do desempenho e sua avaliação, e uma compreensão de que a empresa passa por uma adaptação a um contexto de trabalho culturalmente novo.

Para o dirigente da I é muito mais valorizado o projeto pronto, nele está a inovação, sendo importantes a participação do cliente pelos seus retornos. 0 foco é, assim, no clien- 
te, preocupando-se a empresa de identificar primeiramente a viabilidade dos serviços a ser prestados, como também os cumprimentos de prazos, de modo a garantir um diferencial na qualidade dos serviços, na melhoria do produto final, enfim, nos resultados.

$\mathbf{O}$ dirigente da $\mathbf{F}$ destaca uma inovação na organização do processo produtivo, no que diz respeito à certificação da MPS.br (Melhoria de Processo de Software Brasileiro), e a adoção do modelo linear reverso, de modo a ser primeiro analisadas as necessidades de mercado, seguidas pela geração e pelo desenvolvimento de ideias para, então, se dar a produção e o lançamento de produtos. A adoção de novos serviços, como o fornecimento de soluções na área de inteligência artificial e portais corporativos, também exigem inovação, isto é, um constante aperfeiçoamento técnico e tecnológico, se refletido no quadro funcional da empresa, que adquire características mais flexíveis e abertas a novos profissionais, que, no entanto, são mais exigidos por meio de avaliações quinzenais de produtividade.

No entendimento do dirigente da $\mathbf{M}$, aquilo que eles fazem (jogos para celulares) exige muita criatividade. Além disso, a empresa se insere no ambiente de inovação desenvolvido pelo Porto Digital, de forma que os objetivos da empresa se alinham aos objetivos de outros parceiros do polo tecnológico, como o C.E.S.A.R e a FIR Capital, no que concerne à inovação tecnológica. No entanto, esse dirigente também entende que a empresa acabou por incorporar modelos de comercialização de seus produtos que acabaram não sendo mais convenientes, sendo necessário buscar melhores técnicas e novos mecanismos. Também deixa implícito que essa busca se conduz sob bases do learning by dhangingde tal modo que a empresa aprende a partir de suas tentativas de mudar características operacionais em sua procura por um diferencial competitivo.

Considerando essas atribuições de sentido dos dirigentes e os contextos organizacionais nos quais estão inseridos, o Q uadro 2 apresenta as representações sociais da inovação identificadas como aquelas que mais se destacam no enraizamento de sua compreensão.

\begin{tabular}{|c|l|}
\hline $\begin{array}{c}\text { Dirigente/ } \\
\text { Empresa }\end{array}$ & \multicolumn{1}{|c|}{ Representação social } \\
\hline N & Mudança técnica/ tecnológica e cultural \\
\hline I & Inovação no produto direcionado ao cliente \\
\hline F & $\begin{array}{l}\text { Inovação no processo com ênfase na exce- } \\
\text { lência }\end{array}$ \\
\hline M & Ambiência de inovação \\
\hline
\end{tabular}

Quadro 2: Representações sociais que se enraizam nos dirigentes

Fonte: Elaborado pelos autores, com base nos dados da pesquisa.

\subsection{Relacionando as representações dos dirigentes às classificações da inovação}

As análises apresentadas no item anterior deste artigo são aqui analisadas, considerando como as atribuições de senti- do relativas às representações sociais elaboradas pelos dirigentes e os seus enraizamentos - a partir do contexto organizacional de cada empresa - se relacionam às classificações da inovação constantes na literatura. Para tanto, foi utilizada a tipologia proposta por D amanpour a partir das fontes de inovação, conforme destacaram Moreira \& Queiroz (2007), e que são sintetizadas no Quadro 3 a seguir.

\begin{tabular}{|c|l|}
\hline $\begin{array}{c}\text { Dirigente/ } \\
\text { Empresa }\end{array}$ & \multicolumn{1}{c|}{$\begin{array}{c}\text { Classificação de acordo } \\
\text { com as fontes de inovação }\end{array}$} \\
\hline $\mathrm{N}$ & $\begin{array}{l}\text { Administrativa e técnica e tecnológica; pro- } \\
\text { duto e processo; incremental }\end{array}$ \\
\hline $\mathrm{I}$ & $\begin{array}{l}\text { Administrativa e técnica e tecnológica; pro- } \\
\text { duto; incremental }\end{array}$ \\
\hline $\mathrm{F}$ & $\begin{array}{l}\text { Administrativa e técnica e tecnológica; pro- } \\
\text { cesso; incremental }\end{array}$ \\
\hline $\mathrm{M}$ & $\begin{array}{l}\text { Administrativa e técnica e tecnológica; pro- } \\
\text { duto e processo; incremental }\end{array}$ \\
\hline
\end{tabular}

Quadro 3: Classificando a inovação a partir das representações sociais dos dirigentes

Fonte: Elaborado pelos autores, com base nos dados da pesquisa.

$\mathrm{Na}$ análise verificou-se, em primeiro lugar, que para esses dirigentes não é possível traçar uma distinção entre inovação administrativa e inovação técnica e tecnológica, conforme propõe Damanpour, evidenciando que essas dimensões estão fortemente inter-relacionadas, ou seja, existe a preocupação com a inovação tecnológica dos produtos e das técnicas e tecnologias dos processos produtivos relacionadas às atividades de gestão da organização, mais especificamente operações, marketing e recursos humanos.

Ao mesmo tempo, no que diz respeito a produto e processo, pôde-se inferir que duas das empresas privilegiavam um ou outro. Especificamente, a empresa I, ao focar fortemente 0 cliente, direciona-se ao processo, enquanto a empresa $F$, ao focar mais as operações para o fornecimento dos serviços, dirige-se ao produto. Por outro lado, tanto a empresa $\mathrm{N}$ como a $\mathrm{M}$ acabam direcionadas a ambos, produto e processo. No entanto, a empresa M ocupa-se do produto e do processo, considerando sua inserção em mercados a partir de uma aprendizagem cotidiana, com o fim de gerar um diferencial competitivo, enquanto a empresa $\mathrm{N}$ busca por melhoria interna a partir de uma mudança na cultura corporativa que se quer direcionada ao cliente.

Finalmente, quanto à diferenciação entre inovação incremental e radical, pôde-se perceber que para esses dirigentes não é possível afastar-se das práticas e dos mecanismos usuais das organizações, conforme a sugestão de Moreira e Q ueiroz (2007), a partir de D amanpour. Consequentemente, o que prevalece é uma compreensão prática de que a inovação é algo incremental para todos os quatro dirigentes.

\section{CONSIDERAÇÕES FINAIS}

A partir dos resultados da pesquisa, verificou-se que, apesar de ser proposta uma distinção de D amanpour (1991, apud Moreira \& Queiroz, 2007) para a análise da inovação 
relativa a uma dimensão administrativa e outra técnica e tecnológica, ela não se evidencia na compreensão prática dos dirigentes empresariais que compuseram a amostra. Isso vem confirmar, de certo modo, a proposição de Leonard-Barton (1998) de que a inovação envolve um contexto organizacional amplo relativo às funções gerenciais das empresas.

Também os resultados levam a inferir que a compreensão ampla desses inter-relacionamentos parece mais natural às empresas que têm a inovação como ponto central no direcionamento de suas atividades e a percepção de uma ambiência de inovação na qual estão inseridas, como é caso da empresa $\mathrm{M}$. Isso se justifica, principalmente, quando se considera a outra distinção classificatória de D amanpour num direcionamento maior para o produto ou para o processo. Nota-se que as empresas I e a $\mathrm{F}$ tenderam para um ou para outro; assim a primeira acaba por privilegiar elementos do marketing, enquanto a segunda, elementos da produção e operações.

D eve-se, também, salientar que 0 fato de a empresa $\mathrm{N}$ tender tanto ao processo como ao produto não evidencia a mesma percepção integrada do contexto organizacional baseado na inovação que se explicita na empresa M. No caso da empresa N, o que se pode inferir é uma atribuição à cultura organizacional como base integradora, principalmente quando se destaca a necessidade de uma mudança cultural, e não propriamente um foco na inovação.

Quando considerada a última distinção entre inovação incremental e inovação radical, o que se pode notar é que a primeira prevalece. Entretanto, quando se considera o que diferencia uma da outra, isto é, a primeira baseada em pequenos incrementos e a segunda rompendo valores e práticas, levanta-se o questionamento sobre se o que produziria mudança radical nas empresas seria uma mudança na cultura organizacional - como se explicita no caso da empresa N ou a compreensão da inovação como um fenômeno cultural.

Tal questionamento poderia orientar futuras pesquisas. Também, ressalta-se a necessidade de um maior aprofundamento tanto teórico como metodológico no sentido de investigar a inovação como fenômeno cultural nas organizações, principalmente quando se considera o caráter exploratório e preliminar desta pesquisa. Esse aprofundamento deveria considerar igualmente novos desenhos de pesquisa, a fim de ampliar a compreensão do fenômeno e a possibilidade de sua explicação.

\section{REFERÊNCIAS}

AND REASSI, T. Gestãodaimoraçãotendớg்a São Paulo: Thomson, 2007. BARDIN, L. Análisedeconteádo Lisboa: Edições 70, 1977.

BAUER, M. W.; GASKEL, G. Pesquisa qualitativa com texto imagme sam ummanual prática 2 ed., Petrópolis: Vozes, 2003.

BRASIL. Livobranco Brasília: Ministério da Ciência eTecnologia, 2002. BRULAND, K.; MOWERY, D. C. Innovation through time. In: FAG ERBERG , J., MOWERY, D. C.; NELSO N, R. R. (eds.) Theoxford handbook of innovation O xford: Oxford University Press, 2005, p. 349379.

CAVED ON, N. R.; FERRAZ, D. L. S. Representações sociais e estratégia em pequenos comércios. Reista deAdministraçãodeEmpresas Elerônica, 4 (1), 2005.
CRAMER, L.; BRITO , M. J.; CAPPELLE, M. C. A. As representações sociais das relações de gênero na educação superior: a inserção do feminino no universo masculino. In: ENCONTRO ANUAL DA ASSOCIAÇÃO NACIO NAL DOS PROGRAMAS DE PÓSGRADUAÇÃO EM AD MINISTRAÇÃO, 25, 2001, Campinas. Anais.. Campinas: ANPAD, 2001.

DELLAG NELO, E. H. L.; SILVA, R. A. C. Análise de conteúdo e sua aplicação na pesquisa em administração. In: VIEIRA, M. M. F.; ZO UAIN, D. M. Pesquisa qualitativa emadministraçãa Rio de Janeiro: Editora FGV, 2005.

FAG ERBERG,J.Innovation: a guide to the literature. In:FAG ERBERG, J., MOWERY, D. C.; NELSO N, R. R. (eds.) Theoxford handbook of innovation Oxford: Oxford University Press, 2005, p. 1-26.

G IL, A. C. Métodos etémicas de pesquisa social. 6 ed., São Paulo: Atlas, 2008.

GREY, C. O fetiche da mudança. Revista deAdministraçãodeEmpresa, 44(1), 2004, p. 10-25.

JOVECHLOVITCH S. Representaçães sociais eesfera pública: a construção sinbólica dos esparcos públicos do Brasil. Petrópolis: Vozes, 2000.

KOTLER, P.; ARMSTRONG, G. Pninápios demarketing 12 ed., São Paulo: Ed. Pearson Prentice Hall, 2007.

LEO NARD -BARTO N, D. Nascentes do saber: ciandb e sustentandb as fontes deinovaçãa Rio de Janeiro: Editora FG V, 1998.

MOTTA, P. R. Transfomação arganizacional. São Paulo: Q ualitymark, 1997.

MOREIRA, D. A.; Q UEIROZ, A. C. S. Inovação arganizadianal e teondógica São Paulo: Ed. Thomson Learning, 2007.

MO SCOVICI, S. A representação saial da psicanálise Rio de Janeiro: Zahar, 1978.

NÓ BREGA S. M. O queérepresentaçãosoaial. Tese de D outorado. Ecole Études en Ciences Sociales; França, 1990.

PORTO DIG ITAL. Institucional, 2008. Disponível em: <http:/ / www.portodigital.org/ >. A cesso em: Ago 2009.

OLIVEIRA, L. C.; SORGI, F. A. O poder da inovação no Brasil, 2008. D isponível em: <http:/ / www.cofecon.org.br/ index.php? option $=$ com_content\&task $=$ view\&id $=1357 \&$ Itemid=99 $>$. Acesso em: Jun $200 \overline{9}^{-}$

RANG E L, M. A pesquisaderepresentaçãosocial comofoma deenfrentamento deprddemassocioeducacionais A parecida, São Paulo: Ideias e Letras, 2004. SPINK, M. J. P. O conceito de representação social em psicologia social. Cadkmos deSaúde Pública, 9 (3), 1993, p. 300-308.

VERGARA, S. C.; FERREIRA, V. C. P. A representação de ONG segundo formadores de opinião do município do Rio de Janeiro. Revista deAdministração Pública, 39 (5), 2005, p. 1137-1159.

Data de Submissão: 10/ 08/ 2010

Data de Aprovação: 28/ 10/ 2010 